The Journal of

Thoracic and

Cardiovascular

Surgery

Vol 123, No. 2, February 2002

\title{
What operation for acute type A dissection?
}

John A. Elefteriades, MD

See related article on page 318 .

From the Department of Cardiothoracic Surgery, Yale University School of Medicine, New Haven, Conn.

Received for publication July 23, 2001; accepted for publication Aug 23, 2001.

Address for reprints: John A. Elefteriades, MD, Department of Cardiothoracic Surgery, Yale University School of Medicine, 333 Cedar St (121 FMB), New Haven, CT 06510 (E-mail: john.elefteriades@yale.edu).

J Thorac Cardiovasc Surg 2002;123:201-3

Copyright (C) 2002 by The American Association for Thoracic Surgery

$0022-5223 / 2002 \$ 35.00+0 \quad \mathbf{1 2 / 1 / 1 2 0 3 3 0}$

doi:10.1067/mtc.2002.120330

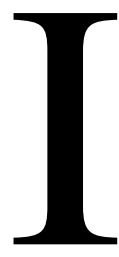

$\mathrm{n}$ their article on surgical treatment of acute type A aortic dissection, Kirsch and colleagues ${ }^{1}$ from the Henri Mondor Hospital have done an excellent job of applying analysis of their considerable experience toward answering fundamental questions regarding how these lesions should be approached. The experience they report is both large (160 cases) and long (20 years). The clinical questions that they pose and their formulation of answers on the basis of this experience are directly pertinent.

The patients reported on by Kirsch and colleagues were extremely sick: $66 \%$ had aortic insufficiency, $25 \%$ were in shock, and $34 \%$ had a malperfusion syndrome. The operations reported in the article were performed with the "closed" technique for the distal anastomosis (crossclamp on) in $86 \%$ of cases. The vast majority of the patients $(81 \%)$ underwent repair with an ascending tube graft with aortic valve resuspension. Twelve percent had a composite graft root replacement, and $4 \%$ underwent separate aortic valve replacement and ascending aortic tube graft. Inhospital mortality was $27.5 \%$. Kirsch and colleagues focused on the need for reoperation in long-term follow-up, examining the implications this late analysis might have on the selection of the appropriate initial operation. Reoperations were equally divided between the proximal aorta (aortic valve or root) and the distal aorta (arch or beyond). Only severe preoperative aortic insufficiency predicted late proximal reoperation. Young patient age, greater distal extent of dissection, and more recent operation predicted late distal reoperation. Kirsch and colleagues concluded that presence of severe preoperative aortic insufficiency merits a more aggressive initial operation (presumably one that incorporates aortic valve replacement).

There are weaknesses inherent in this type of analysis. First, this type of experiential review is of necessity retrospective. As such, it does not provide the opportunity to vary approaches in advance and assess the impact of such variation on outcome. Rather, it relies on inferences drawn from outcome differences between patients treated in different ways. Second, analysis of reoperation rates may miss important impacts of treatment variables that hide in both early postoperative and late mortalities. That is, a patient may have a poor outcome as a consequence of a technical decision in the management of acute type A dissection and die as a consequence, yet never show up as having had a reoperation. Also, patients may harbor untoward sequelae of surgical decisions yet not undergo reoperation for various reasons. Thus, reoperation rates fall far short of telling the whole story.

We have to remember that acute type A aortic dissection is an inherently lethal condition. Our first job is to produce a live patient. If the patient survives the acute episode, this constitutes a success, regardless of later onset of further aortic problems. The early mortality in the series of Kirsch and colleagues was $27.5 \%$. This is not out of line for this disorder, but clearly surgical science still has room for improvement in the treatment of this challenging disorder. Critical to achieving patient survival are complete hemostasis, prevention of intrapericardial bleeding, 
prevention of coronary artery dissection, prevention or correction of major aortic insufficiency, and restoration of flow to compromised branch vessels.

Certain technical truths regarding the surgical management of acute type A dissection are nearly self-evident. One is that performance of a composite graft replacement on an acutely dissected aorta is a dangerous procedure, best avoided if possible. Mobilization and connection of acutely dissected coronary artery buttons is potentially dangerous and problematic. For this reason a supracoronary tube graft is preferred whenever feasible and appropriate. A second technical truth is that an open distal anastomosis permits a more satisfactory technical result. A closed anastomosis always results in a cramped, distorted region at the posterior tip of the clamp, which is a frequent source of bleeding. Also, the mere application of a clamp forces the anastomosis considerably more proximally on the aorta, resulting in a less complete resection of the ascending aorta.

A pertinent physiologic truth is that mild to moderate aortic insufficiency is well tolerated. It is widely known that onset of left ventricular dilatation and heart failure may take many years to become manifest in a general cardiologic patient with aortic insufficiency. Many patients are left with mild to moderate aortic insufficiency after type A dissection repair and do well for many years. This represents a successful outcome, even if further surgical attention is required many years later.

The most important fundamental questions that this and other articles have addressed regarding surgical options in management of acute type A dissection relate to the extent of the operation. Regarding the proximal aorta, does the aortic root need to be replaced? In which patients will a supracoronary tube graft suffice, and in which patients is a more complex resection including the aorta between the valve and coronaries required? Does the aortic valve need to be replaced? Regarding the distal aorta, should the anastomosis be done closed or open? Should the aortic arch be resected, or will it suffice to stay proximal to the origin of the innominate artery?

The technical approach to acute type A aortic dissection that we follow at our institution is supported by a considerable body of recent literature that has examined issues similar to those forming the basis of the report of Kirsch and colleagues. ${ }^{2-14}$ We recommend the following approaches on the issues listed previously.

A simple tube graft suffices in most cases. This does not suffice if the patient has Marfan syndrome, other known connective tissue disorder, or frank annuloaortic ectasia. In such a case composite graft replacement with coronary button implantation is mandatory. Sewing to an ectatic proximal aortic cuff is likely to result in subsequent further dilatation or rupture. Furthermore, technical problems at the time of the acute operation related to sewing to this dilated, weakened tissue are quite common and often lethal. In such instances not only is the patient better served in the long run, but the secure proximal anastomosis to the aortic anulus, which is always strong, is helpful. However, the vast majority of patients with acute type A aortic dissection do not have frank annuloaortic ectasia or Marfan syndrome and can be treated appropriately with a simple supracoronary tube graft.

In most cases the aortic valve can be left alone, or the commissures can be resuspended. Only if the aortic insufficiency is $3+$ or more does the operation need to be prolonged by concomitant aortic valve replacement. Intraoperative transesophageal echocardiography provides an accurate assessment of the severity of the aortic insufficiency before initiation of cardiopulmonary bypass. The severity of aortic insufficiency usually improves even from simple tube graft replacement of the aorta, which brings the aortic valve leaflets closer to coaptation.

An open distal anastomosis is preferable for the technical reasons stipulated previously. The required brief period of circulatory arrest is uniformly well tolerated.

A beveled, hemiarch replacement can usually be easily incorporated into the open distal technique of tube grafting and results in a low rate of subsequent arch aneurysm formation. The question of whether to "chase" an incipient intimal tear that is located not in the ascending aorta (as is overwhelmingly usual) but in the arch proper has not been conclusively answered. This would require a full arch replacement in the face of an acute aortic dissection, an extremely challenging procedure. In such a case although a full arch resection for the arch tear might be strictly preferable for the long-term benefits that could accrue, a tube graft will probably suffice. If the operator feels that full arch replacement is too formidable an undertaking in these circumstances, a tube graft will probably suffice, keeping in mind the all-important goal of producing a live patient at the conclusion of the operation.

One more vitally important technical point deserves to be emphasized. It is generally agreed that in acute type A dissection the two dissected layers should be approximated to obliterate the false lumen. In contrast, for chronic aortic dissection the two layers should not be approximated, because to do so would risk depriving vital organs of circulation that has been flowing through the false lumen.

Although acute type A aortic dissection remains a serious condition, the safety of operation for this pathologic entity may have improved during the 20 years of Kirsch and colleagues' review. Dr Richard Shaw collected (for this commentary) data for our group on survival after surgery for acute type A aortic dissection. Whereas the study of Kirsch and colleagues found a $27.5 \%$ hospital mortality, the mortality in our most recent 5 -year period was 8 of 57 , or $14.0 \%$. 
The relatively new valve-sparing techniques for root replacement are just beginning to be applied to acute type $\mathrm{A}$ dissection. It is too early to speculate on the appropriate role of these operations in this condition.

Acute aortic dissection remains an extremely serious foe, with wiles that will test even the most experienced operator. This condition continues to prove the veracity of Osler's pronouncement some 100 years ago (courtesy of Dr Vincent Gott), "There is no condition more conducive to clinical humility than aneurysm of the aorta."

\section{References}

1. Kirsch M, Soustelle C, Houël R, Hillion ML, Loisance D. Risk factor analysis for proximal and distal reoperations after surgery for acute type A aortic dissection. J Thorac Cardiovasc Surg. 2002;123:318-25.

2. Casselman FP, Tan ES, Vermeulen FE, Kelder JC, Morshuis WJ, Schepens MA. Durability of aortic valve preservation and root reconstruction in acute type A aortic dissections. Ann Thorac Surg. 2000; 70:1227-33.

3. David TE, Armstrong S, Ivanov J, Barnard S. Surgery for acute type A aortic dissection. Ann Thorac Surg. 1999;67:1999-2009.

4. Ehrlich MP, Ergin A, McCullough JN, Lansman SL, Galla JD, Bodian CA, et al. Results of immediate surgical treatment of all acute type A aortic dissections. Circulation. 2000;102(19 Suppl 3);III-248-52.

5. Elefteriades JA, editor. Diseases of the thoracic aorta. Cardiol Clin. 1999:4.
6. Graeter TP, Langer F, Nikoloudakis N, Aicher D, Schafers HJ. Valvepreserving operation in acute aortic dissection type A. Ann Thorac Surg. 2000;70:1460-5.

7. Kazui T, Washiyama N, Muhammad BA, Terada H, Yamashita K, Takinami M, et al. Extended total arch replacement for acute type A aortic dissection: experience with seventy patients. $J$ Thorac Cardiovasc Surg. 2000;119:558-65.

8. Keane MG, Wiegers SE, Yang E, Ferrari VA, St John Sutton MG, Bavaria JE. Structural determinants of aortic regurgitation in type A dissection and the role of valvular resuspension as determined by intraoperative transesophageal echocardiography. Am J Cardiol. 2000;85:604-10.

9. Luciani GB, Mazzucco A. Aortic insufficiency after surgical repair of acute type A aortic dissection: incidence, indications for reoperation and medical management. J Heart Valve Dis. 2001;10:12-8.

10. Niederhauser U, Rudinger H, Kunxli A, et al. Surgery for acute type a aortic dissection: comparison of techniques. Eur J Cardiothorac Surg. 2000;18:307-12.

11. Nguyen B, Muller M, Kipfer B, Berdat P, Walpoth B, Althaus U, et al. Different techniques of distal aortic repair in acute type A dissection: impact on late aortic morphology and reoperation. Eur J Cardiothorac Surg. 1999;15:496-501.

12. Pessotto R, Santini F, Pugliese P, Montalbano G, Luciani GB, Faggian $\mathrm{G}$, et al. Preservation of the aortic valve in acute type A dissection complicated by aortic regurgitation. Ann Thorac Surg. 1999;67:2010-9.

13. Sabik JF, Lytle BW, Blackstone EH, McCarthy PM, Loop FD, Cosgrove DM. Long-term effectiveness of operations for ascending aortic dissections. J Thorac Cardiovasc Surg. 2000;119:946-62.

14. Sinatra R, Melina G, Pulitani I, Fiorani B, Ruvolo G, Marino B. Emergency operation for acute type A aortic dissection: neurologic complications and early mortality. Ann Thorac Surg. 2001;71:33-8. 